\title{
ARAHAN AMALAN JABATAN KEHAKIMAN SYARIAH MALAYSIA DI MAHKAMAH SYARIAH: SUATU SOROTAN LITERATUR
}

\section{Practice Direction of the Department of Shariah Judiciary Malaysia in Shariah Court: A Literature Review}

\author{
Mazni Abdul Wahab \\ Senior Lecturer, Department of Shariah dan Law \\ Academy of Islamic Studies \\ University of Malaya, 50603 Kuala Lumpur \\ mazwa@um.edu.my
}

\begin{abstract}
The issuance of practice direction by JKSM is for the purpose of strengthening the administrative and judicial management of Shariah Courts. This is due to the fact that the existing provisions are still insufficient as its non legal status could lead to the non binding implication. This article will identify previous studies and related researches touching upon practice direction in Shariah and Civil Courts. The study found that the practice direction is over a small part because its a new administrative initiative implemented in Shariah Courts.
\end{abstract}

Keywords: JKSM, practice direction, Shariah Court, procedure

\section{PENDAHULUAN}

Arahan amalan JKSM adalah suatu dokumen bertulis yang dikeluarkan oleh Ketua Pengarah Jabatan Kehakiman Syariah Malaysia (selepas ini disebut JKSM) atau Ketua Hakim Syarie berkaitan dengan prosedur atau polisi yang mana ia perlu diikuti dan dipatuhi walaupun tidak berstatus undang-undang. (Mazni Abdul Wahab et al., 2012: 586) Arahan amalan ini merupakan suatu pendekatan baru yang telah mula diperkenalkan pada tahun 2000. (Ibid: 580) Sesuai dengan penubuhan JKSM pada tahun 1998 yang dipercayai dapat mengatasi permasalahan ketidakseragaman pentadbiran dan kehakiman yang wujud di Mahkamah Syariah sejak sekian lama (Ibrahim Lembut,

* Data-data dalam artikel ini diambil daripada Projek FP030-2016 Universiti Malaya.

Journal of Shariah Law Research (2016) vol. 1 (2) 175-186 
2010; Laporan Tahunan JKSM 2009, 11). JKSM telah mengambil langkah menyediakan satu pelan tindakan dengan mengeluarkan arahan amalan dari masa ke semasa yang merangkumi pelbagai prosedur kehakiman (Abdul Monir Yaacob, 2005: 13).

Arahan amalan Mahkamah Syariah telah diselaraskan melalui JKSM dan untuk memastikan ianya dikuatkuasakan di peringkat negeri, maka Ketua Hakim Syarie Negeri perlu mengendorskannya terlebih dahulu di negeri masing-masing. Pengendorsan oleh Ketua Hakim Syarie negeri merupakan sumber autoriti di Mahkamah Syariah untuk memastikan ianya diterima pakai di peringkat negeri. Jika tidak diendorskan, maka arahan amalan tersebut tidak akan terpakai atau berkuatkuasa di negeri tersebut. ${ }^{1}$ Menurut Tan Sri Sheikh Ghazali Abdul Rahman, arahan amalan telah dijadikan sumber autoriti selain daripada akta ataupun enakmen negeri setelah diendorskan pemakaiannya. ${ }^{2}$ Ini bermakna pengendorsan oleh Ketua Hakim Syarie merupakan titik tolak kepada pemakaian arahan amalan di setiap negeri.

Tujuan diadakan arahan amalan di Mahkamah Syariah adalah untuk menyegerakan penyelesaian kes, menyeragamkan pentadbiran Mahkamah Syariah, memudahkan para hakim membuat rujukan dan sebagainya telah menunjukkan bahawa kewujudannya mempunyai tujuan yang baik serta selaras dengan objektif maqāṣid al-Syarī'ah (Mazni Abdul Wahab, 2014: 78). Arahan amalan yang digunakan ini amat bersesuaian dengan prinsip untuk menjaga agama (al-Dinn) kerana menjaga undang-undang Islam dan harta (al$m \bar{a} l)$ kerana ingin menjimatkan kos dengan mempercepatkan penyelesaian kes dan sebagainya (Ibid.).

\section{PRINSIP PEMAKAIAN ARAHAN AMALAN MAHKAMAH SYARIAH}

Pemakaian arahan amalan Mahkamah Syariah tidak bertentangan dengan hukum Syarak bahkan ianya selaras dengan prinsip-prinsip Syariah. Menurut Shaykh al-Zarqā' (1998: 50) kaedah istiṣlạh adalah selaras dengan prinsip maqāșid al-Syarī'ah. Contoh yang telah diberikan ialah tentang penyusunan

1 Misalnya negeri Kedah tidak diaudit oleh JKSM pada tahun 2005 kerana arahan amalannya tidak diendorskan oleh Ketua Hakim Syarie kerana mempunyai masalah teknikal. Walau bagaimanapun, berdasarkan maklumat semasa hanya arahan amalan tahun 2000 hingga 2007 sahaja yang telah diendorskan pemakaiannya di Kedah.

2 Perutusan Y.A.A. Ketua Pengarah/Ketua Hakim Syarie JKSM iaitu Tan Sri Sheikh Ghazali Hj. Ab. Rahman dalam buku Arahan Amalan Mahkamah Syariah Seluruh Malaysia 2002. 
pentadbiran mahkamah agar lebih kemas, tersusun dan berkesan seperti mengadakan jadual, masa, fail, dokumen dan sebagainya. Maka prinsip ini sama dengan apa yang dipraktikkan melalui pemakaian arahan amalan kerana telah memberikan dimensi baru terutamanya dari segi pentadbiran Mahkamah Syariah supaya menjadi lebih cekap serta menyelesaikan kes seberapa segera yang mungkin.

Arahan amalan juga selaras dengan prinsip memberikan kemudahan kepada pihak-pihak yang berurusan dengan mahkamah (taysìr). Bukti yang menunjukkan Islam itu memberikan kemudahan kepada umatnya dinyatakan dalam firman Allah SWT yang bermaksud:

"(Dengan ketetapan yang demikian itu) Allah menghendaki kamu beroleh kemudahan, dan Ia tidak menghendaki kamu menanggung kesusahan."

(Surah al-Baqarah, 2: 185)

Rasulullah SAW bersabda yang bermaksud:

"Permudahkanlah dan janganlah menyusahkan."

(al-Bukhārī 1400H: 163)

Kedua-dua dalil tersebut jelas menunjukkan bahawa Islam menghendaki kemudahan dan sesuatu yang menyusahkan hendaklah dihindari. Kaedah fiqh yang menunjukkan Islam itu tidak menyusahkan iaitu:

"Kesukaran membawa kemudahan."

Pemakaian arahan amalan dilihat boleh mengelakkan "masyaqqah" di kalangan masyarakat. Di samping itu juga, pemakaian arahan amalan dapat menjaga kemaslahatan orang Islam (mașlahah 'àmmah) apabila disandarkan kepada kaedah: Tașarruf al-Imām 'alā al-Ra 'ìyah Manūtun bi al-Maṣlahah (al-Nadawi1, 1991: 365-367) yang bermaksud "Keputusan pemerintah atas urusan rakyat bergantung kepada kemaslahatan.” Ibn Manzūr (1994: 517) menjelaskan bahawa perkataan mașlahah bermaksud kebaikan yang sama erti dengan makna manfaat. Imām al-Ghazālī (1997: 216) menjelaskan bahawa maṣlahah maksudnya menarik kemanfaatan dan menolak kemudaratan. Menurut Imām al-Rāzī (al-Būṭ̂̀, 1992: 27) mașlahah ialah sesuatu perkara yang membawa kepadanya kemanfaatan dan menolak kemudaratan dan sebab-sebab yang membawa kepadanya. Oleh itu, pihak pemerintah termasuklah Ketua Hakim Syarie yang dilantik oleh pemerintah berhak untuk melakukan apaapa jua yang boleh mendatangkan kebaikan kepada masyarakat termasuklah mengeluarkan arahan amalan. 
Selain dari itu, arahan amalan juga mengambil iktibar daripada peristiwa besar dalam sistem kehakiman Islam berdasarkan kepada utusan surat Khalifah 'Umar al-Khattāō RA kepada hakim Abū Mūsā al-Ash'arī yang dikenali sebagai risālah al-qad̄a ' telah memberi prinsip-prinsip penghakiman kepada para hakim apabila membuat sesuatu penghakiman (Arnus, t.t.: 13; al-Tantari, 1957: 63). Surat ini menjelaskan tentang garis panduan yang wajib diikuti oleh para hakim semasa menjalankan tugas serta menjelaskan tentang prinsip kehakiman yang perlu dipatuhi untuk mencapai matlamat yang sebenar.

\section{LITERATUR MENGENAI SISTEM KEHAKIMAN ISLAM DAN BIDANGKUASA MAHKAMAH SYARIAH}

Terdapat beberapa penulisan terdahulu telah dijadikan landasan teori untuk kajian ini. Kajian dan penulisan mengenai kehakiman Islam telah ditulis oleh Mahmud Saedon Awang Othman (1998 \& 1990), H.F. Amedroz (1910: 761796), Zaini Nasohah (2004: 1-23), Mat Noor Mat Zain (Ibid: 24-63), Amir Husin Mohd. Nor (Ibid: 64-79), Abdul Monir Yaacob (2001: 1-19), Hassan Ibrahim Hassan (1963: 2), Ahmad Mohamed Ibrahim (1997) dan Mohd Saleh Ahmad (2005) dalam penulisan mereka. Penulisan-penulisan ini menjelaskan tentang sejarah kehakiman Islam di zaman Rasulullah SAW dan khalifahkhalifah yang selepasnya. Artikel Zaini Nasohah memberikan kesimpulan bahawa jika ada kelemahan dalam sistem kehakiman ianya adalah berpunca daripada cara ataupun tahap pelaksanaannya dan bukan disebabkan sistem kehakiman yang tidak lengkap. Hassan Ibrahim Hassan menyatakan bahawa keputusan yang dibuat oleh ketua hakim (chief judge) adalah mengikat (binding). Beliau juga menyatakan bahawa tugas seorang ketua hakim tidak terhad kepada kehakiman sahaja kerana mereka turut terlibat dalam kerjakerja kemasyarakatan.

Manakala penulisan mengenai bidangkuasa kehakiman Mahkamah Syariah di Malaysia antaranya dapat dilihat dalam buku yang ditulis oleh Mahmood Zuhdi Hj Abd. Majid (2001) serta artikel-artikel yang ditulis oleh Daud Muhammad (2001: 21-42); Sheikh Ghazali Abdul Rahman (2001: 5169) dan Zalina Zakaria (2005: 215-223). Daud Muhammad membincangkan tentang bidangkuasa Mahkamah Syariah yang terhad hanya kepada orang Islam sahaja. Jika ada kes jenayah Syariah seperti berkhalwat yang melibatkan orang bukan Islam, maka hanya orang Islam sahaja yang akan didakwa. Beliau mencadangkan agar tugas kehakiman Mahkamah Syariah dipertingkatkan selaras dengan ajaran Islam. Sheikh Ghazali Abdul Rahman pula membincangkan tentang sejarah perkembangan Mahkamah Syariah hingga tertubuhnya JKSM. Beliau menyatakan pengurusan kehakiman Mahkamah 
Syariah menjadi lemah disebabkan berlakunya perbezaan dalam Enakmen Pentadbiran Agama Islam serta kaedah dan peraturan yang digunapakai. Beliau menyarankan agar penyelarasan undang-undang, kaedah dan peraturan dilaksanakan bagi mengatasi kelemahan tersebut.

Antara penulisan bidangkuasa kehakiman Islam di negara lain dapat dilihat dalam penulisan H. Taufiq (1989: 45-69), Corocoy D. Mason (1989: 71-85), Elke E. Stockreiter (2010: 560-576), Christian Muller (2000: 57-84), dan Ala'eddin Kharofa (2001: 125-138). Corocoy D. Mason membincangkan tentang kedudukan Mahkamah Syariah di Filipina yang mempunyai bidangkuasa yang terhad hanya kepada undang-undang diri serta beberapa tindakan mal di kalangan orang Islam. Pada pandangan Elke E. Stockreiter, pengaruh penjajahan Inggeris telah mengubah bidangkuasa mahkamah yang asalnya di bawah kekuasaan sultan kepada hanya perkara yang berkaitan dengan undang-undang diri sahaja.

\section{PENULISAN BERKAITAN ARAHAN AMALAN DI MAHKAMAH SIVIL}

Penulisan mengenai pemakaian arahan amalan di Mahkamah Sivil tidak banyak disentuh mungkin disebabkan isu ini bukan lagi baru bagi mereka. Faiza Tamby Chik $(1999 ; 2001: 32)$ telah menulis mengenai arahan amalan dalam artikel yang memaparkan tentang sejarah penggunaan bahasa Inggeris yang dahulunya merupakan bahasa utama di mahkamah. Namun bahasa tersebut telah ditukar kepada bahasa Melayu berdasarkan kepada Perlembagaan Persekutuan. Pertukaran tersebut turut dinyatakan melalui nota amalan, ${ }^{3}$ arahan amalan ${ }^{4}$ dan surat pekeliling. ${ }^{5}$ Manakala Pang Kong Leng (2005) telah

3 Ini adalah berdasarkan Nota Amalan No. 1 Tahun 1989, Nota Amalan No. 2 Tahun 1989, Nota Amalan No. 1 Tahun 1988, Nota Amalan No. 2 Tahun 1988 dan Nota Amalan No. 3 Tahun 1988. Nota-nota amalan ini adalah berkaitan dengan galakan untuk menyeragamkan penggunaan bahasa Melayu di mahkamah dan juga tentang istilah yang sering diucapkan ketika dalam perbicaraan. Contohnya panggilan "My Lord" dan "My Honour" kepada hakim telah ditukar kepada "Yang Arif" mulai 13 September 1988 atas arahan Tun Dato’ Abdul Hamid.

4 Arahan Amalan No. 2 Tahun 1990.

5 Surat pekeliling dan arahan amalan dikeluarkan oleh Hakim Besar Malaya Tan Sri Datuk Hashim Yeop Abdullah untuk menghadapi dan menyelesaikan beberapa kesulitan yang dijangka akan dihadapi dalam tempoh sementara pelaksanaan Bahasa Melayu di Mahkamah Sivil. Contohnya, pekeliling Hakim Besar Malaya No. 2/1990 dan pekeliling Hakim Besar Malaya No. 3 Tahun 1990. Penggunaan Bahasa Melayu ini tidak dihadapi oleh Mahkamah Syariah kerana ianya sememangnya telah menjadi bahasa mahkamah. 
menerangkan tentang cara untuk mengemukakan rayuan di Mahkamah Sivil. Beliau telah memasukkan arahan amalan dan nota amalan yang berkaitan dengan kes rayuan. Terdapat lima belas arahan amalan yang telah disenaraikan berkaitan dengan tatacara rayuan. Walau bagaimanapun, tiada perbincangan terperinci mengenai pemakaian arahan amalan tersebut. Penulisan yang lain telah dilakukan oleh Catherine Elliott dan Frances Quinn (2007-2008: 482) yang menyatakan arahan amalan telah menerangkan peruntukan dalam Civil Procedure Rules. Ini kerana arahan amalan telah memberikan penerangan secara terperinci berkenaan dengan cara untuk memulakan prosiding di mahkamah.

\section{PENULISAN BERKAITAN ARAHAN AMALAN DI MAHKAMAH SYARIAH}

Penulisan mengenai arahan amalan di Mahkamah Syariah dilihat turut dilakukan memandangkan ianya baru diperkenalkan serta timbul beberapa isu selepas pemakaiannya. Penulisan mengenai pemakaian dan tujuan arahan amalan diperkenalkan di Mahkamah Syariah telah disentuh oleh Sheikh Ghazali Haji Abdul Rahman (2005), sesuai dengan kedudukannya sebagai individu tertinggi yang terlibat secara langsung dengan JKSM. Beliau telah menyatakan tentang matlamat arahan amalan diadakan serta penulisannya ini telah banyak membantu penulis dalam memahami arahan-arahan amalan Mahkamah Syariah. Beliau menyatakan hasil daripada pemakaian arahan amalan telah banyak menampung kekurangan yang terdapat dalam undangundang, dapat menyegerakan penyelesaian kes serta dapat menyeragamkan peraturan antara Mahkamah-Mahkamah Syariah. Namun, perbincangan yang dibuat tidak menyentuh tentang cara bagaimana arahan amalan ini dibina serta sejauhmana pemakaiannya di Mahkamah Syariah.

Manakala penulisan-penulisan lain telah dilakukan oleh Ahmad Hidayat Buang (2008), Suwaid Tapah (2007b: 31-54; 2007a: 55-78) dan Ibrahim Lembut (2008: 1-53). Ahmad Hidayat Buang (2007: 145-171) dalam artikel beliau menyatakan bahawa terdapat arahan amalan yang hanya mengulang peruntukan undang-undang serta melampaui peruntukan undang-undang. Beliau berpendapat akibat tidak mematuhi prosedur yang ditentukan dalam arahan amalan tidaklah menyebabkan proses tuntutan terbatal tetapi ianya boleh menjejaskan kelancaran prosiding sahaja. Namun beliau tidak menjelaskan apakah arahan amalan yang dimaksudkan dan sejauhmana kebenaran kenyataan tanggapan tersebut.

Penulisan-penulisan lain yang menyentuh tentang arahan amalan di Mahkamah Syariah telah dibuat oleh Mohd Nadzri Haji Abdul Rahman Ibrahim 
(2010), Tajul Aris Ahmad Bustami dan Mohd Syukri Azaari (2007: 142-163), Mohd Naim Hj. Mokhtar (2003: 1-18), Jasri Jamal (2007), Siti Zubaidah Ismail (2008: 1), serta Muhammad Asri Haji Abdullah (2005). Muhammad Asri bersetuju tentang adanya bidangkuasa penyemakan Mahkamah Tinggi Syariah. Akan tetapi beliau mendapati tiada peraturan yang jelas dalam mana-mana enakmen Mahkamah Syariah mengenai cara bagaimana untuk melaksanakan semakan. Ianya dapat diketahui secara formal apabila arahan amalan dikeluarkan.

Penulis membincangkan tentang bidangkuasa semakan Mahkamah Syariah yang didapati selaras dengan undang-undang Islam serta memaparkan arahan amalan mengenai bidangkuasa ini tetapi tidak membincangkannya secara mendalam. Mohd Nadzri Haji Abdul Rahman Ibrahim pula memfokuskan tentang kehendak Undang-undang Tatacara Mal dan amalan-amalan praktikal di Mahkamah Syariah. Arahan-arahan amalan berkaitan telah dimasukkan untuk menerangkan peruntukan undang-undang yang kurang jelas. Beliau berpendapat Mahkamah Syariah masih lagi kekurangan kaedah-kaedah khusus untuk mengendalikan kes-kes mal. Bagi beliau, arahan-arahan pentadbiran termasuklah arahan amalan masih boleh disangkal keesahannya.

Penulisan di peringkat kedoktoran yang telah dijalankan tidak menjadikan arahan amalan sebagai topik utama tetapi hanya menyatakan adanya arahan amalan yang berkaitan dengan topik mereka dan tidak membincangkannya dengan lebih lanjut. Antaranya, kajian yang dilakukan oleh Raihanah Azahari (2005 \& 2008), Zaini Nasohah (2007), dan Jasni Sulong (2005). Kajian Zaini Nasohah membincangkan tentang masalah dalam melaksanakan perintah nafkah iaitu nafkah isteri dan nafkah anak.

Beliau mengkaji permasalahan yang berlaku di negeri Selangor. Dalam hal ini, beliau mendapati punca-punca yang menyebabkan perintah yang telah dikeluarkan oleh pihak mahkamah tidak dapat dilaksanakan dengan baik adalah disebabkan oleh tuntutan dibuat hanya kepada bapa, prosiding saman penghutang penghakiman kurang sesuai digunakan, ketiadaan alamat terkini pemiutang penghakiman, kekurangan bailif dan banyak lagi. Untuk mengatasi permasalahan yang sedia ada, beliau telah mencadangkan agar tempoh kecuaian membayar nafkah, jumlah kekerapan yang membolehkan si pemiutang boleh membuat permohonan mengurangkan ansuran bayaran nafkah (jika benar-benar mampu tetapi sengaja enggan membayar) dibuat arahan amalan. Beliau juga menyarankan agar tugas bailif dilaksanakan sebagaimana yang dinyatakan dalam arahan amalan.

Raihanah Azahari pula membincangkan tentang konsep sulh dalam Islam serta amalannya di Mahkamah Syariah Negeri Selangor. Peranan seseorang 
pegawai sulh amat penting untuk memastikan Majlis Sulh yang diadakan dapat berjalan dengan lancar. Beliau mendapati ada sulh yang diamalkan menyimpang daripada konsep asalnya. Beliau ada menyentuh sedikit mengenai arahan amalan berkaitan laporan sesi kaunseling Jabatan Agama Islam Negeri (JAIN) untuk kes perceraian. Dalam hal ini, arahan amalan tersebut menyatakan laporan tersebut tidak perlu diajukan ke mahkamah. Namun beliau tidak bersetuju dengan arahan amalan yang menyatakan tidak ada keperluan untuk mendapatkan laporan dari sesi kaunseling daripada JAIN. Bagi beliau, mahkamah syariah yang menjadi rujukan awal pihak-pihak yang ingin bercerai sepatutnya memberikan ruang untuk pihak-pihak mendapatkan nasihat serta berunding sebelum dibenarkan untuk bercerai. Akan tetapi, pendapat beliau ini telah tidak dipersetujui oleh Suwaid Tapah apabila menyatakan arahan amalan ini wajar diikuti untuk mengelakkan kelewatan penyelesaian kes.

\section{RUMUSAN}

Arahan amalan yang diperkenal dan digunapakai di Mahkamah Syariah adalah satu langkah dalam kerangka prinsip Siyāsah Syar 'īyyah yang mesti diikuti, dipatuhi serta diterimapakai selagi mana ianya tidak bertentangan dengan hukum Syarak. Kepatuhan terhadap arahan amalan adalah kerana ianya merupakan arahan yang dikeluarkan oleh Ketua Hakim Syarie negeri yang mendapat kuasa melalui perlantikan oleh Sultan atau DYMM Seri Paduka Baginda Yang DiPertuan Agong maka sewajarnya arahan amalan diterima pakai oleh semua kakitangan dan mereka yang berurusan dengan Mahkamah Syariah.

Manakala penulisan dan kajian mengenai arahan amalan dan pemakaiannya di Mahkamah Syariah yang bersifat menyeluruh masih belum banyak diusahakan oleh pengkaji-pengkaji, baik dahulu mahupun sekarang. Ini disebabkan arahan amalan merupakan kaedah yang baru dilaksanakan di Mahkamah Syariah, maka tulisan-tulisan mengenai arahan amalan lebih berbentuk bahagian kecil.

\section{RUJUKAN}

Abdul Monir Yaacob (2001). "Konsep Kehakiman Islam," dalam Sistem Kehakiman Islam, ed. Abdul Monir Yaacob. Kuala Lumpur: IKIM.

Ala'eddin Kharofa (2001). "The Judicial System of Islam with Special Reference to Some Muslim Countries," dalam Sistem Kehakiman Islam, ed. Abdul Monir Yaacob. Kuala Lumpur: IKIM. 
Ahmad Hidayat Buang (2008). "Penulisan Teks Penghakiman dalam Perundangan Islam," dalam Penulisan Teks Penghakiman di Mahkamah Syariah, ed. Ruzman Md. Noor. Kuala Lumpur: Universiti Malaya.

Ahmad Hidayat Buang (2007). "Prosedur Mal di Mahkamah Syariah," dalam Undang-Undang Islam di Malaysia Prinsip dan Amalan, ed. Ahmad Hidayat Buang. Kuala Lumpur: Penerbit Universiti Malaya.

Ahmad Mohamed Ibrahim (1997a). "Sistem Kehakiman Islam di Malaysia Masa Kini," dalam Undang-undang Pentadbiran Islam di Malaysia. Kuala Lumpur: IKIM.

Ahmad Mohamed Ibrahim (1997b). "Peranan Hakim dan Pegawai di Mahkamah Syariah," dalam Undang-undang Pentadbiran Islam di Malaysia. Kuala Lumpur: IKIM.

Ahmad Mohamed Ibrahim (1997c). "Bidangkuasa dan Kuasa MahkamahMahkamah Syariah: Hakim dan Pegawai Syariah," dalam UndangUndang Pentadbiran Islam di Malaysia. Kuala Lumpur: IKIM.

Ahmad Mohamed Ibrahim (1997d). "Hakim, Pegawai Undang-Undang, Pegawai Hal Ehwal Islam: Persepektif dan Undang-undang," dalam Undang-Undang Pentadbiran Islam di Malaysia. Kuala Lumpur: IKIM.

Amir Husin Mohd. Nor (2004). "Wanita dalam Kehakiman Islam," dalam al-Syariah Kehakiman Islam, Siti Zalikhah Haji Md. Nor et al. Kuala Lumpur: DBP.

Arnus, Muḥammad Maḥmūd (1984). Tarīkh al-Qaḍ̄' fì al-Islām. Qāhirah: alMatba'ah al-Mișriyyah.

Daud Muhammad (2001). “Tugas Kehakiman dalam Mahkamah: Pengalaman dalam Mahkamah Syariah," dalam Sistem Kehakiman Islam, ed. Abdul Monir Yaacob. Kuala Lumpur: IKIM.

Al-Būṭ̂̄, Muḥammad Sa'id Ramaḍān (1992). Dawābiṭ al-Maṣlaḥah fì alSyarī'ah al-Islāmīyyah. Beirūt: Muassasah al-Risālah.

E.E. Stockreiter (2010). "British Kadhis" and "Muslim Judge": Modernisation, Inconsistencies and Accommodation in Zanzibar's Colonial Judiciary." Journal of Eastern African Studies, vol. 4 (3).

Elliott, Catherine \& Frances Quinn (2008). English Legal System. United Kingdom: Pearson Education.

Faiza Haji Tamby Chik (1999). "Kehakiman Mahkamah Sivil," dalam Perkembangan Undang-Undang Perlembagaan Persekutuan, Ahmad Ibrahim et al. Kuala Lumpur: DBP.

Faiza Haji Tamby Chik (2001). Mengenal Mahkamah Malaysia. Kuala Lumpur: DBP. 
Al-Ghazālī, Muhammad Ibn Muhammad (1997). al-Mustaşfā min 'Ilm alUșūl. Beirūt: Dār Ihyyā' al-Turāth al-'Arab̄i.

Ibn Manẓūr, Muhammad Ibn Mukarram Ibn 'Alī (1994). Lisān al-'Arab. Lebanon: Dār al-Ṣadr.

Ibrahim Lembut (2008). "Kaedah dan Keseragaman di dalam Cara Pembahagian Harta Sepencarian Harta Pusaka Islam.” Jurnal Hukum, vol. 25 (1).

Jasri Jamal (2007). "Isu Pelantikan dan Etika Peguam Syarie," dalam Kaedah Perundangan Bidang Kuasa dan Tatacara Mahkamah Syariah, ed. Tajul Aris Ahmad Bustami et al. Kuala Lumpur: DBP.

Hassan Ibrahim Hassan (1963). "Judiciary System from the Rise of Islam to 567A.H.” Re Islamic Quarterly, vol. VIII.

H.F. Amedroz (1910). "The Office of Kadi in the Ahkam Sultaniyya of Mawardi." Journal of Royal Asiatic Society of Great Britain and Ireland.

H. Taufiq (1989). "The Role of Judiciary in the Development of Islamic Law: The Indonesian Experience." Syariah Law Journal IIUM, December.

Jasni Sulong (2005). "Undang-Undang Pusaka Islam: Kajian Terhadap Pembaharuan Undang-undang dan Aplikasinya di Malaysia." Tesis Kedoktoran, Jabatan Syariah dan Undang-undang, Akademi Pengajian Islam, Universiti Malaya.

Mahmood Saedon Awang Othman (1998). Institusi Pentadbiran UndangUndang \& Kehakiman Islam. Kuala Lumpur: DBP.

Mahmood Saedon Awang Othman (1990). Kadi Perlantikan Perlucutan dan Bidangkuasa. Kuala Lumpur: DBP, 1990.

Mahmood Zuhdi Hj Abd. Majid (2001). Bidangkuasa Jenayah di Mahkamah Syariah. Kuala Lumpur: DBP, 2001.

Mason, Corocoy D (1989). "The Shariah Courts: Their Relation to the Development of Islamic Law in the Philippines." Syariah Law Journal IIUM, December.

Mat Noor Mat Zain (2004). "Pelantikan Hakim," dalam al-Syariah Kehakiman Islam, ed. Siti Zalikhah Haji Md. Nor et al. Kuala Lumpur: DBP.

Mazni Abdul Wahab, Ahmad Hidayat Buang \& Narizan Abdul Rahman (2012). "Arahan Amalan: Pelaksanaannya di Mahkamah Syariah di Malaysia." The Law Review, Sweet \& Maxwell Asia.

Mazni Abdul Wahab (2014). "Pemerkasaan Mahkamah Syariah Melalui Pemakaian Arahan Amalan Jabatan Kehakiman Syariah Malaysia." Tesis Kedoktoran, Jabatan Syariah dan Undang-undang, Akademi Pengajian Islam, Universiti Malaya. 
Mohd Nadzri Haji Abdul Rahman Ibrahim (2010). Undang-Undang Tatacara Mal Mahkamah Syariah Prinsip dan Amalan. Negeri Sembilan: Karya Kreatif Resources.

Mohd Naim Hj. Mokhtar (2003). "Permohonan Ex-Parte dan Perintah Interim di Mahkamah Syariah," dalam Harta Sepencarian Prosiding Ex-Parte Perintah Injunksi, ed. Tajul Aris Ahmad Bustami et al. Selangor: Universiti Islam Antarabangsa.

Mohd Saleh bin Ahmad (2005a). "Kelayakan Seorang Hakim (Qadi) Menurut Pandangan Islam." Risalah Ahkam. Selangor: Intel Multimedia and Publication.

Mohd Saleh Ahmad (2005b). "Kebebasan Institusi Kehakiman dalam Islam." Risalah Ahkam. Selangor: Intel Multimedia and Publication.

Mohd Saleh Ahmad (2005c). "Pengaruh Budaya Tempatan dalam Menentukan Kredibiliti Qadi Atau Hakim." Risalah Ahkam. Selangor: Intel Multimedia and Publication.

Mohd Saleh Ahmad (2005d). "Perlantikan Wanita Sebagai Hakim dalam Sistem Kehakiman Islam." Risalah Ahkam. Selangor: Intel Multimedia and Publication.

Muhammad Asri Haji Abdullah (2005). "Bidangkuasa Pengawasan dan Penyemakan Mahkamah Tinggi Syariah.” Jurnal Hukum, vol. XX (II), November.

Muller, Christian (2000). "Administrative Tradition and Civil Jurisdiction of the Cordoban Sahib al-Ahkam." al-Qantara, XXI.

Mușțafā Aḥmad al-Zarqā' (1988). al-Istiṣlah wa Maṣāliḥ al-Mursalah wa Uṣūl Fuqahā'. Damsyiq: Dār al-Qalam.

al-Nadawī, 'Alī Aḥmad (1994). al-Qawā id al-Fiqhiyyah (Dimashq: Dār alQalam.

Pang Kong Leng (2005). Legal Guide to Civil Appeals Malaysia. Singapore: $\mathrm{CCH}$ Asia Pte. Limited.

Raihanah Azahari (2008). Sulh dalam Kes Kekeluargaan Islam. Kuala Lumpur: Universiti Malaya.

Raihanah Azahari (2005). "Sulh dalam Perundangan Islam: Kajian di Jabatan Kehakiman Syariah Selangor." Tesis Kedoktoran, Jabatan Fiqh dan Usul, Akademi Pengajian Islam, Universiti Malaya.

Sheikh Ghazali Abdul Rahman (2001). "Perkembangan Terkini Mahkamah Syariah di Malaysia," dalam Sistem Kehakiman Islam, ed. Abdul Monir Yaacob. Kuala Lumpur: IKIM. 
Sheikh Ghazali Abdul Rahman (2005). "Amalan-Amalan Pentadbiran di Mahkamah Syariah.” Jurnal Hukum, vol. XX (II), November.

Siti Zubaidah Ismail (2008). "Dasar dan Amalan Penghukuman Kes Jenayah Syariah di Mahkamah Syariah: Ke Mana Halatuju?” Jurnal Hukum, vol. 27 (1) Disember.

Suwaid Tapah (2007a). "Harta Sepencarian (Harta Perkahwinan)," dalam Undang-Undang Islam di Malaysia Prinsip dan Amalan, ed. Ahmad Hidayat Buang. Kuala Lumpur: Penerbit Universiti Malaya.

Suwaid Tapah (2007b). "Prosedur Perceraian," dalam Undang-Undang Islam di Malaysia Prinsip dan Amalan, ed. Ahmad Hidayat Buang. Kuala Lumpur: Penerbit Universiti Malaya.

Tajul Aris Ahmad Bustami \& Mohd Syukri Azaari (2007). "Permohonan ExParte dalam Kes Hadanah," dalam Kaedah Perundangan Bidang Kuasa dan Tatacara Mahkamah Syariah, ed. Tajul Aris Ahmad Bustami et al. Kuala Lumpur: DBP, 2007.

al-Tantari, 'Alī (1957). Ikhbār 'Umar wa Ikhbār 'Abd Allāh Ibn 'Umar. Beirūt: Dār al-Fikr.

Zaini Nasohah (2004). "Institusi Kehakiman Islam," dalam al-Syariah Kehakiman Islam, ed. Siti Zalikhah Haji Md. Nor, et al. Kuala Lumpur: DBP.

Zaini Nasohah (2007). "Penguatkuasaan dan Pelaksanaan Perintah Nafkah: Kajian di Mahkamah Syariah Selangor (1999-2004).” Tesis Kedoktoran, Jabatan Syariah dan Undang-undang, Akademi Pengajian Islam, Universiti Malaya.

Zalina Zakaria (2005). "Shariah Courts Jurisdiction in Malaysia: Notes on Recent Development and Cases," dalam Mahkamah Syariah di Malaysia Pencapaian dan Cabaran, ed. Ahmad Hidayat Buang. Kuala Lumpur: Penerbit Universiti Malaya, 2005. 